\title{
Service Learning: A Bridge to Engineering for Underrepresented Minorities
}

\author{
Abiola A. Farinde \\ Post-Doctoral Research Fellow \\ Center for Urban Education \\ University of Pittsburgh \\ afarinde@pitt.edu
}

\author{
Brett Tempest \\ Assistant Professor \\ Civil and Environmental Engineering \\ University of North Carolina at Charlotte \\ bqtempes@uncc.edu
}

\author{
Lisa Merriweather \\ Assistant Professor, Educational Leadership \\ University of North Carolina at Charlotte \\ lmerriwe@uncc.edu
}

\begin{abstract}
Female, Black, Latino and Native American students are underrepresented in the STEM pipeline. Finding ways to increase underrepresented populations in STEM fields continues to be a major initiative in education. Many underrepresented student groups express a strong orientation toward service and community engagement. Informal Science Education (ISE) can be structured to include community engagement and to engage learners' interest and enhance their understanding of the theory and practice of science. Service learning is a strategy that can be used within an ISE pedagogy to highlight how engineering acts as a community engaged vocation. This report describes a service learning project that exposed underrepresented high school aged students to engineering via a community service activity in which students built irrigation equipment for use in a community garden. The objective of the project was to use the context of service learning to motivate high school students to consider STEM majors. To describe the impact of informal science education through service learning, a qualitative study was also conducted. Three themes emerged: experiential learning (learning while doing), broadening perspective and identity as performance. Lessons learned and strategies for improving the service learning design are also discussed.
\end{abstract}

Index - engineering; informal science education; service learning; STEM; underrepresented students

\section{INTRODUCTION}

Learning through informal education has occurred throughout the history of humankind Livingstone describes it as "(1) a new significant form of knowledge, understanding or skill acquired outside a prescribed curricular setting and (2) the process of acquisition, either on your own initiative in the case of self-directed informal learning, or with aid of a mentor in the case of informal training, respectively." "He also adds that informal learning occurs "when teachers or mentors take responsibility for instructing others without sustained reference to an intentionallyorganized body of knowledge in more incidental and spontaneous learning situations, such as guiding them in acquiring job skills or in community development activities." ${ }^{2}$ Informal education can be integrated into any academic discipline. 
Holmes believes that informal education within science education (ISE) can be key to motivating students to learn about science. She says, "Connections need to be made between science and the world in which students live. In other words, science needs to be related to the students' real-world experiences" 3 and recommends the use of "alternative learning environments" and alternative strategies. ISE holds great promise for not only teaching secondary students about science but also for motivating students, particularly underrepresented students, to consider a STEM related college major. Service learning is a teaching innovation that is one such alternative strategy, which can be adopted as a form of ISE, but it has been underexplored as a pedagogical strategy that can be used by both formal classroom teachers and agents of informal science education in community-based organizations.

This article describes an ISE community service activity completed during fall, 2013 called Bridge to Engineering. The activity, which was the key component of the service learning project, exposed African American and Latino high school aged students to engineering majors and careers via a community service activity in which students' built irrigation equipment for use in a community garden. The objective was to use the context of the service learning project to motivate high school students to consider STEM majors by: 1) illustrating the potential for STEM careers to be socially engaged and oriented towards amelioration of community problems, 2) building an engineering self-image and self-efficacy within the high-school and college student participants through reflection and 3) conveying the preparation requirements necessary to matriculate to STEM majors upon entering college.

This project was funded through an internal funding program called the Chancellor's Diversity Challenge Grant established at the University of North Carolina at Charlotte. The objective of this grant is to support faculty, staff and student initiatives that promote the daily value of diversity in the intellectual life of the campus. One method of promoting this value is by increasing the diversity of students in the pre-college pipeline. Research indicates most future scientists developed their interest in science as a profession while in high school. ${ }^{5}$ However, many students, especially female students, who begin high school with aspirations to enter a STEM field, abandon the idea by graduation time. ${ }^{6}$ Consequently, the STEM pipeline is plagued by chronic underrepresentation of female, Black, Latino and Native American students resulting in representation sharply differentiated along gender and racial boundaries.

Examination of the causes of under representation indicates that it is linked to both inadequate pre-college preparation ${ }^{7}$ as well as weaker interest in careers associated with STEM majors. ${ }^{8}$ The issue of preparation is not examined in this paper, but has been considered by many researchers. ${ }^{9} 10$ 11 The potential link between lack of interest in STEM careers and misperceptions about the nature of the work serves as the basis for the design of the service learning project.

Researchers discovered that community engagement during college and post-college is a stronger priority expressed by many underrepresented student groups. ${ }^{12}$ The Higher Education Research Institute publishes an annual snapshot of entering freshman classes, which provides a 40- year history of demographics and student attitudes. The Institute reported that amongst all student groups there has been a resurgence of altruistic values. ${ }^{13}{ }^{14}$ However, even though all students are rapidly embracing an orientation towards service, the same literature shows an even stronger affinity by students attending historically Black colleges and universities. This desire to serve suggests that underrepresented minorities may be choose other career options because engineering is perceived as a vocation with low community engagement. Selvan asserts, "All human endeavors including engineering and science have, or at least ought to have, the 
betterment of humanity as their primary objective."15 However, some STEM careers such as engineering are often perceived as being detached from community engagement. In other words, it is not construed as a helping community-service profession in the same way that being a medical doctor is understood.

The ERA Foundation commissioned an evaluation of public perceptions of engineering in the UK. They found that among other issues misperception reigns throughout the general public. The visual image from which the public conceptualized engineering careers was of "hard hats and tool belts. ... [with] little space for creativity or innovation. . . . when engineers create an innovative solution, develop a product, or complete a project, they do not sing from the rooftops, they merely quietly pride themselves on a job well done"16. The ERA Foundation discovered that "fantastic examples of the innovative solutions developed by engineers[,] ranging from a solarpowered fridge used to keep medication cool in the third world, a magnet capable of measuring gas levels in canisters, or even a single-use syringe thought to be responsible for saving 60 million lives" $" 17$ are often invisible to the general public. The invisibility results in engineers receiving little acknowledgement for contributing to the betterment of society beyond built structures. We postulate that embedding service learning into learning about engineering may help to provide a more balance picture. A positive outcome of linking engineering with service is that it may increase the appeal to chronically underrepresented groups in STEM fields.

\section{Project Overview}

The Bridge to Engineering program was designed as ISE. It included both alternative teaching strategies and alternative learning environments. It integrated service into an instructional plan that was designed to link the social issue of hunger and food supply with the engineering challenge of providing a sustainable irrigation solution at a local community garden managed by Friendship Gardens. The food grown in the Friendship community gardens is donated to the local Meals on Wheels program. The equipment constructed was sufficiently complex to require engineered design, but appropriate for the capabilities of the participants. Additionally, college-aged engineering students mentored the secondary students and helped to engage them in reflective practice as they completed the construction.

Bridge to Engineering sought to recruit high school aged participants who were college-able, and STEM-interested, but undecided about attending college or selecting a major. College-able indicates that the students were academically qualified by their high-school performance to enter a four-year college program. STEM-interested means that the students had an affinity for STEM topics, but not a strong commitment to select a STEM major. The Police Activities League (PAL), a community organization that engages approximately 1,000 local youth in a variety of extracurricular activities, after-school programs, and college preparation pursuits, agreed to recruit students from their enrichment programming to participate in the service learning project. PAL was active in pre-engineering enrichment activities through a robotics club that it supported and thus the program organizers believed that a pool of college-able, STEM interested, but undecided students could be recruited to participate in the project. Further, PAL was selected as the community partner because the Bridge to Engineering objectives were consistent with PAL's mission to perform community service and to provide educational enrichment. While PAL engaged in recruitment efforts, not all the student participants met the qualifications of collegeable, STEM-interested, and undecided regarding college enrollment and major. Participants that were recruited by PAL self-selected into the program and were not formally or informally screened prior to the start of the program. As a result many of the participants who arrived for 
the first day of the program were students who had already decided on a career in science and a few were not on an academic trajectory in terms of grades or present abilities to major in engineering in college. All students who arrived on the first day of the program were permitted to participate.

While the majority of the participants in the service-learning project were African American, there was one Latino student. Unfortunately, only one female student opted to participate in the service-learning project. Due to conflicts in schedules, all participants did not attend on every Saturday. On average, 12 students were in attendance at each session.

Providing information and mentorship from STEM professionals who were similar to the self-image of the students were additional strategies employed to help stimulate interest in STEM careers. The campus' Engineers Without Borders (EWB) student organization was a coauthor of the Chancellor's Diversity Challenge grant and six of its students representing various racial and gender backgrounds volunteered to serve as activity facilitators and mentors. Because participation in community service activities is an expectation of the organization, neither course credit nor compensation was needed as incentive for EWB student participation.

\section{Project Description}

The project itself consisted of designing and constructing a solar powered irrigation system that stored and distributed collected rainwater. The selection of the project scope was intentional to include aspects of each of the three primary undergraduate engineering disciplines. The pumping and piping aspects of the project appealed to students who might have interest in mechanical engineering. Collecting, cleaning, and storing rainwater are linked to civil engineering. The photovoltaic collection, storage and control system has clear connection to electrical engineering. Finally, the environmentally "green" aspects of the project, such as solar energy collection, rainwater harvest and local farming, were included and highlighted to appeal to millennials, who increasingly espouse an affinity for sustainability. The project unfolded over the course of four consecutive Saturday sessions, each lasting approximately six hours.

During the first Saturday, students were introduced to their mentors, played icebreaker games and were oriented to aspects of engineering as a career. After lunch they met a representative from the beneficiary organization, Friendship Gardens. His presentation provided the critical link between the work that students would do during the project and the alleviation of the community problem of hunger. He clarified how aspects of the project, such as the pumps being powered by solar energy in absence of an electrical connection and avoiding a costly water connection process by using the system stored rainwater, were linked to the mission of the organization to provide healthy food to the community's Meals on Wheels program, Friendship Trays. In the afternoon of the first Saturday, the students conducted exploratory experiments in each of the three fields of engineering. For instance, they measured the output of small solar cells in various lighting conditions in the electrical experiment, created pump efficiency curves in the mechanical experiment and measured roof runoff generation in the civil engineering experiment (Figure 1). After this exploratory day, the students were asked to select a discipline specific team for the remaining project phases. 


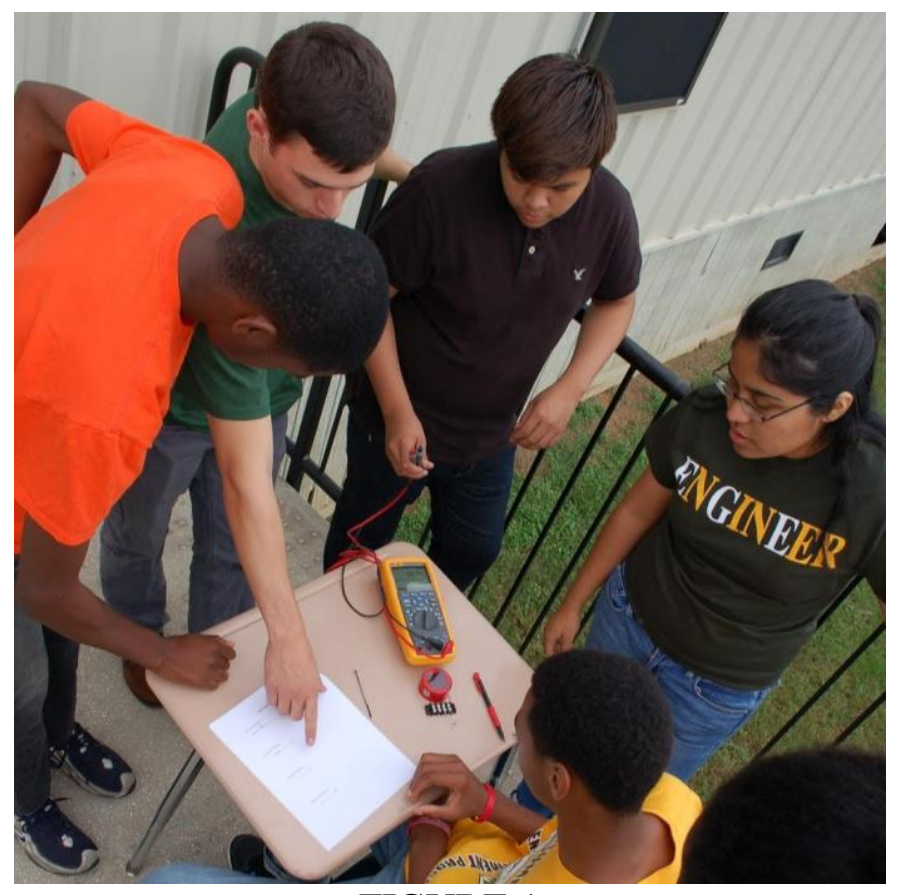

FIGURE 1

\section{STUDENTS MEASURE THE OUTPUT OF A SMALL SOLAR CELL AS PART OF A PRIMER ON ELECTRICITY}

During the second Saturday session, the students split into their disciplinary teams to undertake design tasks. The scope of these design tasks was narrowed to enable the students to focus on aspects that were appropriate to their skill and knowledge level. For instance, the civil engineering team tackled the task of designing a "first flush" system that discards the first quantity of rainwater that enters the system since this portion is most likely to carry contaminants from the roof. The conceptual design of the system was presented to the students, and then they assumed responsibility for sizing various components and planning the pipe layout. Most of the design activities took place at the project site, and students had access to parts and materials in order to experiment with potential designs (Figure 2). The two other groups undertook similar design tasks related to the solar charging system and the pumping system. The scope of each design team's tasks is described in Table 1. 
TABLE 1

DESIGN TASKS ASSIGNED TO EACH DISCIPLINARY GROUP

\begin{tabular}{|l|l|}
\hline \multicolumn{1}{|c|}{ System Component } & \multicolumn{1}{c|}{ Design Tasks } \\
\hline Energy Storage & $\begin{array}{l}\text {-Estimation of energy requirements for lighting and } \\
\text { pumping } \\
\text {-Design of battery storage } \\
\text {-Design of required wattage/number of solar panels }\end{array}$ \\
\hline Water Collection and Storage & $\begin{array}{l}\text {-Estimation of roof runoff quantities } \\
\text {-Estimation of irrigation quantity requirements } \\
\text {-Design of first flush system }\end{array}$ \\
\hline Pumping and Plumbing & $\begin{array}{l}\text {-Estimation of head and flow requirements } \\
\text {-Selection of pump parts } \\
\text {-Design of pump control system }\end{array}$ \\
\hline
\end{tabular}

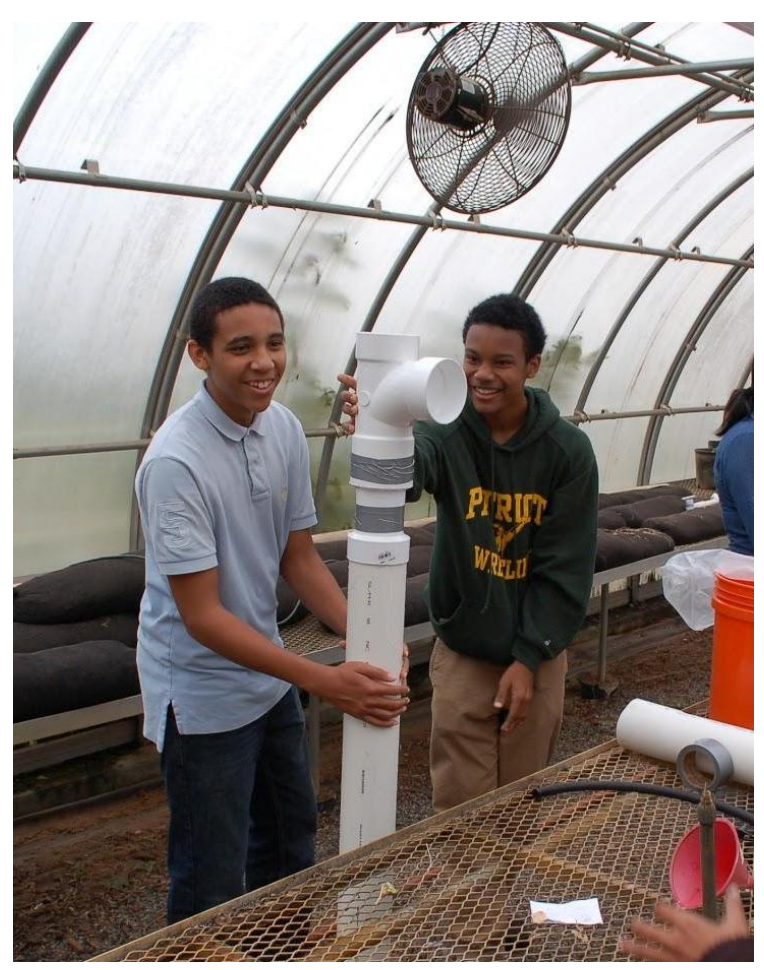

FIGURE 2

STUDENTS DESIGN A FIRST FLUSH DIVERTER FOR THE RAINWATER HARVEST SYSTEM 
On the third working day, the students constructed the systems that they designed during the previous week (Figure 3). Although the students primarily remained in their disciplinary groups, some special teams were formed to build components that linked the three main subsystems together. The construction project required more labor than the small high school and college student group could accomplish during the work period, so additional community members were invited to join. The extra volunteers were recruited from the Friendship Garden network as well as the university community. This created an excellent opportunity for students to continue informal discussions regarding the benefits of the project to the community as well as about their future education and career plans. Each of the project's subsystems was operational at the close of the Bridge to Engineering program.

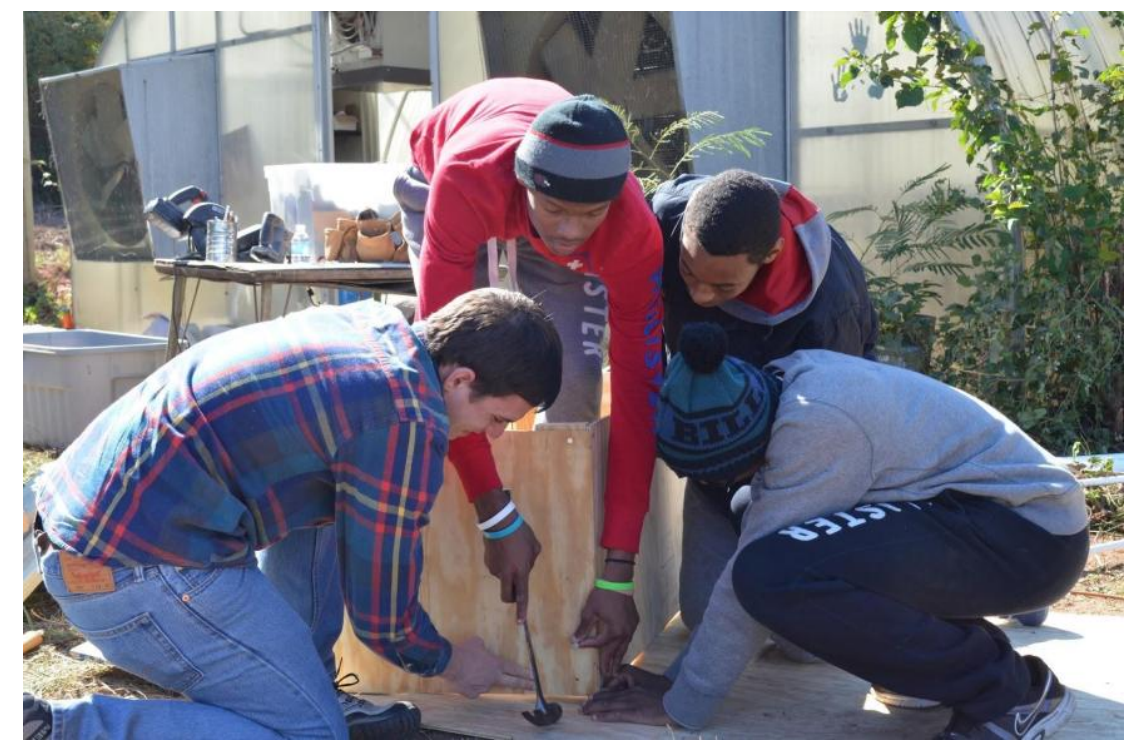

FIGURE 3

\section{STUDENTS WORK WITH THEIR COLLEGE STUDENT MENTOR TO BUILD A COMPONENT OF THE SOLAR POWERED PUMP SYSTEM}

On the final Saturday session, students reflected, reported their accomplishments and celebrated completion of the program with family. Invitations to join the group for lunch and a project showcase were distributed to the families of the student participants. The final session was held at the university rather than the worksite in order to better accommodate the activity. The students were provided with poster-making materials, including prints of pictures that were taken during the working days. The high school students worked with their college student mentors to reflect on the significance of the systems that they had designed and constructed. The pressure of an impending presentation to parents and project stakeholders motivated the students to quickly collect their thoughts. Each disciplinary group prepared a poster describing the sub-system for which they had responsibility. Parents, siblings and extended family joined the students for showcase presentations in the afternoon (Figure 4). Following the presentations, the students and their families were escorted on a tour of the College of Engineering facilities, including classrooms, computer labs, laboratory spaces and student areas. 


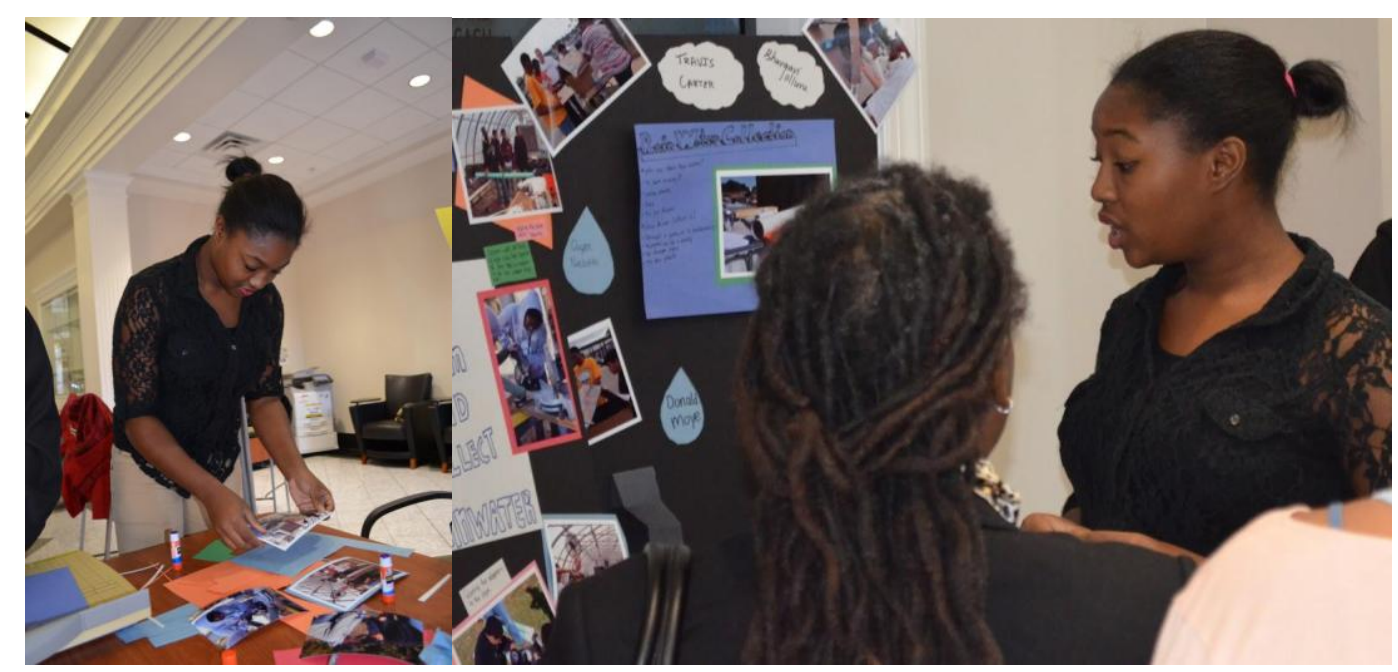

FIGURE 4

STUDENT PARTICIPANT PREPARES AND PRESENTS HER POSTER TO PEERS AND PARENTS

The project included many aspects of the service learning methodology. Jenkins and Sheehey ${ }^{18}$ indicate that there are four elements to service learning projects: preparation, implementation, assessment/reflection, and demonstration/celebration. Preparation included the collaborative planning of the service-learning project. This collaboration occurred on two levels - between the EWB college students and the EWB engineering faculty advisor and between the EWB college students and the program participants. ISE often juxtaposes experts and non-experts in close proximity, but without the boundaries and hierarchies that would typically limit communication between these two groups in more formal environments, like classrooms. The EWB college student mentors were sufficiently competent with the science and engineering subject matter related to the project to accurately address inquiries for information from the secondary school participants during the planning and implementation phases of the project. The EWB college student mentors provided both lessons on the engineering concepts as well hands on experiences to understand the content and complete the construction. Driven by the need for additional details as they designed the subsystems of the irrigation scheme, information was provided using a "just in time" model. As both the student participants and EWB college student mentors discovered gaps in needed knowledge, appropriate information was given to continue movement on the project. These gaps often were uncovered during informal formative assessments by EWB college mentors posing questions and observations of the student participants as well as during the reflection phases of the service-learning project. The EWB college students built in purposeful time for the students to assess what they knew, to demonstrate what they learned, and to voice uncertainty and confusion about the learning. The collaborative nature of the project resulted in many occasions for students to switch to the role of teacher or expert amongst their peers during the Saturday work sessions and with their family members during the celebration and demonstration phase of the service learning project. 


\section{Outcomes}

To assess the impact of the service-learning project on the student participants, a qualitative case study was conducted. Qualitative studies do not measure or seek to predict phenomenon but rather provide rich analytic descriptions based on the data gathered. Findings are formed from patterns identified in the descriptions of the data. The qualitative case study had three data sources: focus group with student participants, focus group with EWB college student mentors, and an individual interview with the PAL Club coordinator and Friendship Gardens representative. Additionally an informal assessment of perceptions of engineering was conducted on the first Saturday of the program. The informal assessment was embedded within an introductory/ice breaker activity through which the students introduced themselves and discussed their understanding of what engineers do (See Appendix A). The participant focus group (See Appendix B), EWB college mentor focus group and individual interviews (See Appendix B) were completed at the conclusion of the program. A \$10 gift card was offered to each student who elected to be in the focus group. The graduate research assistant hired to work on this project facilitated the interviews.

The analysis (assessment of the data) was completed by one of the faculty program organizers and the graduate research assistant after the interviews had been transcribed verbatim. All of the data from the focus groups and individual interviews was inductively analyzed and themes were developed using a constant comparative coding strategy ${ }^{19}$. This involved reading each line of data for words and phrases meaningful to the research purpose then clustering those words and phrases based on emerging patterns, and similarities and applying a code. Codes were then compared to each other to form larger conceptual categories by either combining the codes or further delineating their differences. This process of constant comparative coding resulted in three themes/outcomes: (1) Experiential learning enhanced comprehension of engineering concepts (learning while doing), (2) Students broadened their perspectives about the engineering field, and (3) Students constructed an engineering identity through performance of engineering tasks.

\section{Experiential Learning (Learning While Doing)}

Informal science education (ISE) is not bound by conventional methods of teaching. It often involves using methods that are experiential. Experiential learning (learning while doing) is active, real-time, and relevant learning that often occurs in an environment more natural to the learning situation. Service learning was the vehicle used to engage the student participants in experiential learning. It provided a platform for learning about engineering concepts through reflection on the act of "doing" engineering in addition to engaging in applied engineering tasks. Experiential learning proved to be an essential element for developing and refining the skills, competencies, and present knowledge of the youth participants. The use of tactile learning added a dimension to the experience that reinforced the engineering concepts the equipment was designed to meet. Experiential learning integrates multiple senses into the learning experiences. This integration engaged the learners in ways that went beyond the scope of simply listening to a lecture, it also involved the practice of reflection. Through individual and group reflections, students gained in-depth knowledge of not only the engineering-related equipments' purpose and functions but also confidence in their potential role in engineering.

In the construction phase, through trial and error and reflecting on their collective and individual methods, the youth began to understand the importance of engineering in ensuring proper functioning of the equipment. Having the opportunity to problem solve when the 
equipment did not work correctly, execute solutions, and see the results of their critical thinking in real-time provided a feedback loop with immediate reinforcement. As co-contributors in the service-learning project, students directed the projects' pace. The project only moved forward after the students understood how the equipment functioned to meet the objectives of the service learning project. Their ideas, reflections and actions were instrumental in completing all assignments in the project. For example, Chris, a high school project participant, describes his perception of his experiences during the service learning project. He outlines how experiential learning and reflection assisted in the internalization of knowledge. Chris recounted his experience:

'We like started everything from the base. It wasn't like they cut parts for us and then we put it together. We had to start from like the very beginning. And also, like helping out, [and] being able to design it...they weren't limiting us to like, ok, this is going to be the template, so you need to come up with that. It was more like just think what you wanna think and then we'll try to help you get that together.'

In addition to being active participants in the design and construction of the solar-powered water pump system for the large-scale community garden, experiential learning allowed the youth to take on various leadership roles within their designated groups. Teaching and learning were fluid among all project participants, meaning high school students moved beyond their role as receivers of knowledge and transitioned to creators of knowledge. They did not passively accept new information; rather, at each phase of the service learning project problem-posing was used as a strategy to actively involve the high school students in the learning process. This environment allowed them to repositioned themselves as teachers by adding to discussions and offering their college mentors suggestions regarding each assignment. Teaching back what they had learned, participating in dialogic problem solving through math and science related tasks and critically thinking about how best to accomplish each task reinforced the knowledge of the subject matter and increased their self-efficacy as science learners. The experiential nature of ISE through the service learning project resulted in increased confidence in their engineering abilities.

\section{Broadened Perspectives}

A second outcome was the broadening of students' perspectives of engineering. Prior to the service learning project, students had a narrow and often distorted understanding of the engineering field and of engineers. The high school participants associated engineers with mainstream, media images, such as construction workers and Bob the Builder and Handy Manny, animated characters from children's television programming. In addition, students frequently noted that they perceived engineers as "mad scientists in lab coats." The "mad scientist in lab coats" persona was characterized by the students as too smart, strange, unsociable and un-relatable, qualities that starkly contrasted with the students' perceived identities. Possessing these inaccurate views about engineers and generalizing all engineers as mad scientist framed students' initial understanding of what it meant to be an engineer. In regards to the engineering profession, students' level of understanding was limited to mechanical engineering, unclear about the work of other disciplines within engineering (i.e., electrical, civil, etc.). At the conclusion of the service learning project, the focus group revealed that students demonstrated a broader perspective about engineers and the engineering field. They were able to distinguish 
between different positions within the engineering field as well as adopt a more accurate representation of engineers than they articulated during the ice breaker activity. Eric explained how he learned that there is a distinction between the different types of engineers. He firmly asserted his new found understanding of the engineering profession:

'About the different engineers, I learned that there's more than one. I thought there was one that built everything but I learned that there is like electrical, and civil, and all of that and like they do different things.'

Likewise, when asked whether the service learning project changed or expanded his thoughts on what engineers do, Michael indicated that the project expanded his prior knowledge base. At the beginning of the project, Michael, in fact, had somewhat of a foundational, yet simplistic grasp of the tasks engineers perform. His statement below makes clear that he has a broader understanding of the engineering profession. He states:

'I say expand because now I know more than I did before. Like I just thought engineers like fixed cars and build things.'

\section{Identity as Performance}

Students were taught about diverse engineering disciplines and careers (e.g., electrical, mechanical and civil) and participated in distinct work groups within the service learning project in which they performed tasks associated with a particular engineering discipline. The hands-on experiences in their respective work groups not only reinforced their capabilities, but also aided in the development of their engineering identity. Experiential learning resulted in students claiming ownership of the identity of an engineer. Julian stated, "I felt like an engineer" during the focus group interview. This echoed the sentiments of other students as well. At each stage of the project (classroom learning, designing, constructing and presenting), students performed different engineering tasks, positioning themselves within the field of engineering.

As the high school students began to see themselves as engineers, they also conveyed a greater sense of self-efficacy and confidence in their role and performance as engineers within the service learning project. John, the PAL supervisor, as well as the EWB college mentors, observed students displaying greater confidence. John affirmed:

'I think a lot of them (high school project participants) gain self-confidence. And to some extent a higher level of self -esteem. '

The budding confidence in their abilities strengthened their engineering identity. An example was seen in how students successfully answered application problems posed by their mentors. Trevor, an undergraduate mentor, recalled the experience.

'Because we were trying to trick them with like one of the pumps like we made it look like really good and like there was this one little thing that wasn't going to work for it and they all caught it and I was like darn. Cause I was kind of hoping for them to pick the wrong thing so we could teach them, but they all like got it. I was like alright that's it then.' 
He explained how he thought the students were going to incorrectly answer the question; however, they answered the question with confidence. The analysis of the data supports that engineering tasks, assignments and reflection engendered an engineering identity and inspired self-confidence among the high school participants.

\section{Lessons Learned}

In addition to the findings relative to the students' perceptions developed from the interview data indicated above, many lessons were also learned about managing a service learning project as a form of ISE. The program was conducted in an area of town familiar and accessible to the participants. This is a logistical element that we would seek to preserve when we facilitate the program in the future because it reduced transportation costs for the participants and allowed the participants to feel more comfortable. Timing of the program was also reconsidered. The program was conducted over four successive Saturdays during the fall semester. Because many of the fall sports occurred on Saturdays, this time of year proved to be an extremely busy time for the participants and may have limited the available pool of participants. Feedback from the parents included shifting from fall to spring. This timing shift has some conceptual grounding as well since spring is the start of the growing season. Another lesson learned was with respect to the spacing between sessions. Four Saturdays straight may have limited interest in participation not just for the students but for the EWB college mentors. The college mentors proved to be a valuable asset to the program. The students found the mentors readily approachable and relatable most likely due to their age. For future programs, we are considering meeting every other Saturday or meeting for two Saturdays with a week recess followed by the final two Saturdays or perhaps offering it as a week-long summer camp on campus.

In addition to the logistical lessons learned, we also realized that the curriculum needed refining. The college engineering students, who had the content knowledge but lacked pedagogical knowledge, developed the lessons. Though this limitation impacted the effectiveness of the lessons, the EWB college mentor involvement in the lesson planning was crucial. It not only reinforced their knowledge of engineering but it also gave them a sense of ownership in the process. In other words, they were fully invested in the success of the learning activities. In planning for the next program offering, we have enlisted the assistance of a student in science education. This student will help to shape the curriculum and help to coach the college engineering students on facilitation strategies. The science education student will also assist in integrating the idea of community engagement into the lessons to create a more explicit connection between the work of engineers and community engagement.

Finally, greater emphasis will be placed on screening participants. The students who were a part of the first implementation of the program were good and seemed to gain a great deal as a result of participating in the program, but as mentioned, many had already decided on a career in science and a few were not on an academic trajectory in terms of grades or present abilities to major in engineering in college. The STEM interested and STEM committed population and those who have an interest but not the grades are certainly appropriate targets for enrichment programs; however, we are specifically interested in understanding how a program of this nature can influence those students who are science-interested and college ready but not necessarily committed to a career in STEM. Developing a system to ensure that this population of students participates in the program is a key lesson learned from the first round of the program. 


\section{Success Stories}

Tania, the sole African American female participant, displayed a growing interest in engineering as the project progressed. At the beginning her interest level was low. In fact to get her to participate, Tania's mom promised her daughter breakfast each Saturday morning from a popular fast food chain if she attended the service learning project and told her if she was not enjoying the experience, she could call her mother to pick her up. As the project progressed, Tania flourished, not only comprehending the complex concepts but also actively engaging and leading hands-on engineering related tasks within her group. Beyond a surface level understanding, Tania articulated how and why certain processes were executed and what effects they would produce. Through the collaborative work team and initial mastery of engineering jargon developed during the service learning project, she began to recognize herself as an engineer. As one graduate mentor expressed, "I really saw a spark of interest in Tania. She [may] not be going down this route, but she definitely sees [engineering] as a opportunity." From Tania's viewpoint, her explanation below shows her initial disinterest in engineering, and how through exposure to the engineering field, her viewpoint was altered, becoming more open to the possibility of entering the field. She began to understand how her math and science skill set might be well suited for a career in engineering. Tania explains her changed perspective:

'I think I had no interest for engineering at first, like none at all. I always wanted to be in the medical field because my family was and but now, I realize where they're certain things that I feel that I could apply if I was an engineer like, I'm good at math, and I like science, obviously. So it's just [looking] into the different aspects of [engineering and deciding] if I wanted to be more environmental or if I wanted to be more civic and in the community and doing [projects].'

Jaden, a Black male participant, also showed great interest and excitement toward engineering as a result of being involved in the service learning project. Jaden began informing his peers and teachers about the service learning project and his role in the completion of project assignments. John, the PAL coordinator, related a conversation he had with Jaden.

'[Jaden] told me, "Mr. Smith, I love it!" He was telling his friends. Actually when I walked up on him, he was telling another friend about the program. I was at his school maybe two weeks ago and when I walked up on him, he's there telling about the project to a friend of his. And his friend wanted to participate in it at the time.'

Jaden, with fervor, disseminated information about his positive experiences as an engineer with his friends who were not in the program. The positive experience of the participants proved to be yet another sign of success that had the unintended consequence of those participants being ambassadors for engineering as a viable and exciting career choice. Though Tania, Jaden nor their peers conveyed a desire to pursue engineering because of its service-oriented component, it was clear that the service-learning project resulted in increased knowledge about engineering and a greater willingness to consider it as a profession.

Another project success occurred during the last day of the program. Students and their families were invited to campus. They were provided lunch and a tour of the engineering building. The students also received certificates of participation. The main event was a poster session in which the students explained the mechanics and the purpose of the tools they built. 
This presentation helped to further cement the knowledge the students attained but moreso was included to showcase the work they completed and their pride in working on the service learning project. An unanticipated element that was observed was the parent interaction. As they circulated through the poster session, they asked questions of the students and talked among themselves. As we overheard conversations, it was clear that the parents gained a new appreciation for what their children were capable of doing and developed a greater appreciation for the ways in which ISE could promote an interest in STEM careers for their children.

One parent in particular stood out. During a conversation with one of the organizers, she indicated that her son was not at all interested in participating in the program. She signed him up and she made him attend. One the first morning, he reluctantly came to the program. When she picked him after the first day of participating in the day's activity, he was so excited that he could not stop talking about it. He gained a new understanding of what it meant to "do science." He not only looked forward to attending the remaining sessions but wanted to recruit his friends for the program as well. While it was validating to hear that the program's interactive experiential format had a powerful impact on the student, it was equally validating to hear the parent's endorsement of the process. Parents play a pivotal role in encouraging interest in STEM careers.

\section{CONCLUSIONS}

In conclusion Informal Science Education (ISE) can enhance not only students understanding of science but also their interest in science as a field of study. Engineering has historically been an area of study with low participation from African American, Latino/Latina, Native American and female groups. Literature on the importance of community engagement on career choice suggests that careers with perceived high levels of community engagement may be more attractive to those populations. When service learning is included within ISE, it can help demonstrate the various ways that community engagement is embedded in the work of engineering. Experiential learning strategies were shown to be instrumental for meeting the service learning project's objectives. This project illustrated that while ISE with a service learning component does increase both subject matter knowledge, perspectives of what engineering entails, and identification as an engineer, more deliberate and conscious efforts need to be made to create a bridge to engineering for underrepresented students through community engagement engendered through service learning. 


\section{APPENDIX A}

\section{Introduction}

Tell them your name and what you are majoring in college (no need to give a lot of explanation about engineering or why you choose engineering because we want to know what they know before starting this project).

Welcome them to the project and tell them you want to get to know them.

Everyone should answer these first two questions

1) Ask them their names and what do they want to do when they grow up.

2) Ask what are the two most important things that attract them to their future job answers might include
a. Money
b. Time/flexibility
c. Helping others
d. Working with others
e. Being Creative
f. etc

3) Ask if anyone knows anyone who has a career in the sciences? If they give you blank stares, offer some suggestions like doctor, engineer, chemists, etc. (I am sure you can come up with a better list).

4) Choose three and ask them to describe what they do (You can get 2 or 3 responses for each description). The ones to be described should include a (1) typical helping profession such as doctor; (2) engineering; (3) your choice.

5) Read the list and by show of hands which you will record ask which of these jobs involve helping people and/or working in the community
a. Secretary
b. Teacher
c. Doctor
d. Welder
e. Engineer
f. Dentist
g. Police
h. Chemist
i. CIA Agent
j. Accountant
k. Performing Artist

6) So of these jobs, which do you think are the ones that have the potential to help people the most? The least? (if this list could be on a poster/newsprint sheet that would be great) 
7) Okay last question, by show of hands who is ready to have some fun and learn some really cool stuff? (please rephrase in better language that might not sound so hokey)

8) Thank them for their time and send them to join the other EWB students.

\section{APPENDIX B}

\section{PAL Student Focus Interview Questions}

How many have ever done something like this before?

What was the best part about working on this service learning project?

What was the worst part about working on this service leaning project?

What did you learn from working on this service learning project?

Tell me what you learned about what engineers do as a result of working on this project. Think about your first day, what did you think about what engineers do that is the same? Different?

Based on your experience, tell me about how you see engineering as a profession that helps others/ a profession that is engaged with the community?

Would knowing that a career had a high potential for helping others and being engaged in the community influenced your career choice?

What motivates you career choice?

Has working on this project increased your interest in working in engineering? Why or Why not?

\section{APPENDIX C}

\section{Community Partner \& Engineers Without Borders Interview Questions}

Have you ever participated in a service learning project with school age children? Share with me your impressions of the service learning project What was your involvement with the children during this project?

What were your thoughts about the children as they participated in the project?

Affect: Excited, bored, disinterested, happy, etc,

Behavior: on task, engaged, off task, playing around

Cognitively: seemed to get the big picture, didn't see a connection to helping others/community engagement.

From your vantage point, was this service learning project effective in helping to...

Pique the interest of students in STEM

Pique the interest of students in Engineering

What was it about the program that led you to answer as you did?

Concluding thoughts 
International Journal for Service Learning in Engineering

Special Edition, pp. 475-491, Fall 2014

ISSN 1555-9033

\section{REFERENCES}

${ }^{1}$ David W. Livingstone, Adults' Informal Learning: Definitions, Findings, Gaps and Future Research (Toronto: Centre for the Study of Education and Work, Ontario Institute for Studies in Education, 2001), 5-6.

${ }^{2}$ Livingstone. Adults' Informal Learning: Definitions, Findings, Gaps and Future Research, 3.

3 Julie Holmes, "Informal Learning: Student Achievement, and Motivation in Science through Museumbased Learning," Learning Environments Research 14 (2011): 264.

${ }^{4}$ Holmes. "Informal Learning: Student Achievement, and Motivation in Science through Museum-based Learning," 264.

${ }^{5}$ Steve Olson, ed. Strengthening High School Chemistry Education Through Teacher Outreach Programs: A Workshop Summary to the Chemical Sciences Roundtable (National Academies Press, 2009).

${ }^{6}$ Philip M. Sadler, Gerhard Sonnert, Zahra Hazari, and Robert Tai. "Stability and Volatility of STEM Career Interest in High School: A Gender Study." Science Education 96, no. 3 (2012): 411-427.

${ }^{7}$ Robert H. Tai. "Career Choice: Enhanced: Planning Early for a Career in Science." Science, 1 (2006): 02 .

${ }^{8}$ Gary S. May and Daryl E. Chubin. "A Retrospective on Undergraduate Engineering Success for Underrepresented Minority Students." Journal of Engineering Education 92, no. 1 (2003): 27-39.

${ }^{9}$ Peter Arcidiacono, Esteban M. Aucejo, and V. Joseph Hotz. University Differences in the Graduation of Minorities in STEM Fields: Evidence from California. No. w18799. (National Bureau of Economic Research, 2013).

${ }^{10}$ Edward C. Kokkelenberg and Esha Sinha. "Who Succeeds in STEM Studies? An Analysis of Binghamton University Undergraduate Students." Economics of Education Review 29, no. 6 (2010): 935 946.

${ }^{11}$ Laura Perna, Valerie Lundy-Wagner, Noah D. Drezner, Marybeth Gasman, Susan Yoon, Enakshi Bose, and Shannon Gary. "The Contribution of HBCUs to the Preparation of African American Women for STEM Careers: A Case Study." Research in Higher Education 50, no. 1 (2009): 1-23.

${ }^{12}$ Lorelle L. Espinosa. "Pipelines and Pathways: Women of Color in Undergraduate STEM Majors and the College Experiences that Contribute to Persistence." Harvard Educational Review 81, no. 2 (2011): 209-241.

13 The American Freshman: National Norms Fall 2010. Higher Education Research Institute, University of California, 2010.

${ }^{14}$ Sandra Dika and Jae Hoon Lim, "Critical Review of Research on the Role of Social Engagement" (Paper Presented at the Annual Meeting for the American Society for Engineering Education, San Antonio, Texas, 2011).

${ }^{15}$ Krishnasamy T. Selvan. "An Approach for Harmonizing Engineering and Science Education with Humaneness." Science and Engineering Ethics 10, no. 3 (2004): 573-577.

${ }^{16}$ Changing Perceptions: Opening People's Eyes to Engineering. ERA Foundation, Surrey, UK, 2014. Retrieved from http://www.erafoundation.org/changing-perceptions-opening-peoples-eyes-toengineering/

${ }^{17}$ Changing Perceptions: Opening People's Eyes to Engineering. ERA Foundation.

${ }^{18}$ Amelia Jenkins and Patricia Sheehey. "A Checklist for Implementing Service-Learning in Higher Education." Journal of Community Engagement and Scholarship, 4, no. 2 (2012): 52-60.

${ }^{19}$ Kathy Charmaz. Constructing Grounded Theory: A Practical Guide Through Qualitative Analysis (Sage, 2006). 